\title{
The consequences of ubiquitous expression of the wingless gene in the
}

\section{Drosophila embryo}

\author{
JASPRIEN NOORDERMEER ${ }^{1}$, PAUL JOHNSTON ${ }^{2}$, FRANS RIJSEWIJK ${ }^{3, *}$, ROEL NUSSE $^{1}$ and PETER A. \\ LAWRENCE ${ }^{2}$ \\ ${ }^{1}$ Howard Hughes Medical Institute and Department of Developmental Biology, Stanford University, California 94305-5428, USA \\ ${ }^{2}$ MRC Laboratory of Molecular Biology, Hills Road, Cambridge CB2 2QH, England \\ ${ }^{3}$ Division of Molecular Biology, Netherlands Cancer Institute, 1066 CX Amsterdam, The Netherlands \\ *Present address: Central Veterinary Institute, Lelystad, The Netherlands
}

\section{Summary}

The segment polarity gene wingless has an essential function in cell-to-cell communication during various stages of Drosophila development. The wingless gene encodes a secreted protein that affects gene expression in surrounding cells but does not spread far from the cells where it is made. In larvae, wingless is necessary to generate naked cuticle in a restricted part of each segment.

To test whether the local accumulation of wingless is essential for its function, we made transgenic flies that express wingless under the control of a $h s p 70$ promoter (HS-wg flies). Uniform wingless expression results in a complete naked cuticle, uniform armadillo accumulation and broadening of the engrailed domain. The expression patterns of patched, cubitus interruptus Dominant and Ultrabithorax follow the change in engrailed.

The phenotype of heatshocked HS-wg embryos resembles the segment polarity mutant naked, suggesting that embryos that overexpress wingless or lack the naked gene enter similar developmental pathways.

The ubiquitous effects of ectopic wingless expression may indicate that most cells in the embryo can receive and interpret the wingless signal. For the development of the wild-type pattern, it is required that wingless is expressed in a subset of these cells.

Key words: Drosophila melanogaster, wingless, ectopic expression, segmentation.

\section{Introduction}

Five hours after fertilization, the Drosophila embryo exhibits the first morphological signs of repeated units that will form the segments of the larva and adult fruit fly (reviewed by Lawrence, 1992). A gene essential for correct formation of this pattern is wingless; in its absence, the precisely banded pattern in the larval cuticle is replaced by a continuous field of denticles (Babu, 1977; Nüsslein-Volhard and Wieschaus, 1980). The wingless gene is also needed to form the wing and a variety of adult structures; in wingless ${ }^{1}$ mutants the group of cells that should make the wing sometimes become misdirected to duplicate a part of the thorax (Sharma and Chopra, 1976; Morata and Lawrence, 1977).

In the Drosophila embryo, wingless is expressed in a precise pattern, initially in narrow stripes of cells that line the parasegment borders on their anterior sides (Baker, 1987; van den Heuvel et al., 1989). wingless is a member of the class of segment polarity genes. Mutations in these genes affect the cuticle pattern of every segment. Some sixteen segment polarity genes have been identified and several have been cloned: armadillo (Riggleman et al., 1989), cubi - tus interruptus Dominant (Orenic et al., 1990), fused (Préat et al., 1990), gooseberry (Baumgartner et al., 1987), engrailed (Fjose et al., 1985; Kornberg et al., 1985), patched (Hooper and Scott, 1989; Nakano et al., 1989), shaggy/zeste-white3 (Bourouis et al., 1990; Siegfried et al., 1990) and wingless (Baker, 1987; Rijsewijk et al., 1987). Zygotic transcripts from these genes can be first detected towards the end of the blastoderm stage as the cells form; from then on cell interactions are likely to be important in maintaining and elaborating pattern.

The predicted molecular structures of several segment polarity gene products are consistent with roles in intercellular signaling: fused and shaggy/zeste-white 3 are putative serine-threonine kinases, patched encodes a putative transmembrane protein and armadillo is related to $\beta$-catenin (McCrea et al., 1991) and plakoglobin (Peifer and Wieschaus, 1990), proteins associated with cell-cell junctions. An indication that wingless might play a role in these interactions is that the gene is necessary to maintain engrailed expression in adjacent cells, shown by the disappearance of engrailed in wingless ${ }^{-}$embryos, just after gastrulation (DiNardo et al., 1988; Bejsovec and MartinezArias, 1991; Heemskerk et al., 1991). Moreover, the two 
genes are interdependent; in engrailed ${ }^{-}$embryos wingless expression decays prematurely (Martinez-Arias et al., 1988).

wingless is also necessary for local distribution of armadillo protein, most likely by some form of post-transcriptional control (Riggleman et al., 1990). wingless encodes a cysteine-rich protein with a signal peptide (Rijsewijk et al., 1987). The protein is secreted, becomes associated with the extracellular matrix (van den Heuvel et al., 1989) and can apparently spread from cells in which it is made into nearby cells (van den Heuvel et al., 1989; Gonzáles et al., 1991).

The wingless gene is highly conserved; there are both vertebrate and Drosophila homologs (The Wnt gene family; reviewed by Nusse and Varmus, 1992) and there are indications that these genes behave similarly to the wingless gene product; the mammalian Wnt-1 protein is also secreted and presumably retained by the cell surface or the extracellular matrix (Papkoff and Schryver, 1990; Bradley and Brown, 1990) and can influence the behaviour of cells in close proximity (Jue et al., 1992). In general, the wingless and Wnt proteins may all be necessary for regional specification of groups of cells. No receptor for any of these molecules is known.

One way to test whether the local distribution of the wingless protein is important in determining cell fate is to alter the wingless distribution in embryos. We have therefore made transgenic flies that express the gene under the control of a heatshock promoter. Universal expression of the protein produces a striking phenotype, suggesting that most cells can respond to the wingless signal. This phenotype strongly resembles that produced by a mutation in the segment polarity gene naked.

\section{Materials and methods}

\section{Construction of pHS-wingless plasmid and generation of transgenic flies}

A construct was made which consists of a 231 bp XhoI-AluI fragment of the promoter region of the $h s p 70$ gene from clone $56 \mathrm{H} 8$ (Moran et al., 1979), cloned in front of $2.9 \mathrm{~kb}$ wingless sequence containing its own polyadenylation signal. The XhoI site of the $h s p 70$ promoter region is located at $-188 \mathrm{bp}$ and the $A l u \mathrm{I}$ site is located at +43 bp with respect to the transcription start site (Török and Karch, 1980). The XhoI site was made blunt ended and to the $A l u \mathrm{I}$ site a BamHI linker was ligated. The wingless sequence consists of a $1.2 \mathrm{~kb} F n u$ DII-EcoRV cDNA fragment (with a BamHI linker at the FnuDII end) ligated to $1.7 \mathrm{~kb} E c o \mathrm{RV}-P v u \mathrm{I}$ genomic sequence. This construct was cloned into the $\mathrm{HpaI}$ site of the Pelement vector Carnegie 20, containing the rosy gene as a marker and injected into rosy ${ }^{506}$ flies together with the pII 25.1 WC helper plasmid (Karess and Rubin, 1984). One line was obtained that contained a single P-element insertion at position $66 \mathrm{~A} / \mathrm{B}$ on the third chromosome. This stock was homozygous viable.

\section{Fly stocks}

All flies were maintained at $23^{\circ} \mathrm{C}$ on medium containing agar, yeast and glucose. For the study of the effect of heatshock on cuticle phenotype, homozygous HS-wg flies were used, while rosy ${ }^{506}$ flies were used as a control. Embryos of the strains HS$w g / \mathrm{TM} 3 \mathrm{Sb}$ and Canton $S$ were used for antibody stainings and
RNA in situs. A stock was made that contain the HS-wg construct and a $\beta$-galactosidase-marker gene: eve- $\beta$-gal; HS-wg/TM3Sb which has a P-element inserted on the first chromosome, containing the $\beta$-galactosidase gene driven by the even-skipped promoter (Lawrence et al., 1987).

The naked alleles $n k d^{7 E 89}$ and $n k d^{7 \mathrm{H} 16}$ were a gift from $\mathrm{C}$. Nüsslein-Volhard.

\section{Heatshock procedure and larval cuticle preparation}

The effect of heatshock on cuticle pattern was studied in embryos homozygous for the HS-wg construct. Eggs were collected on apple-juice plates for 4 hours, washed in PBS and $0.1 \%$ Triton (X-100) transferred to slides and covered with 3 S-oil. Staging of the embryos was done according to Wieschaus and Nüsslein-Volhard (1986). Groups of embryos of a particular stage were picked out, transferred to Eppendorf tubes and submerged in a waterbath at $36^{\circ} \mathrm{C}$ for 20 minutes. At the end of the heatshock period, the embryos were placed on apple-juice plates and allowed to develop. After two days the embryos were dechorionated, devitellinized by hand and mounted in Hoyer's medium to study the cuticle phenotype (Wieschaus and Nüsslein-Volhard, 1986). rosy ${ }^{506}$ embryos were used as a control for the general effects of heatshock on embryonic development. Heatshocked rosy ${ }^{506}$ embryos mostly hatched with normal cuticle pattern. In some cases, larvae were found with fused denticle belts.

For antibody stainings and RNA in situs, embryos were collected from HS- $w g / T M 3 S b$ flies. Embryos were collected for 5 hours, aged for 1 hour and heatshocked for 20 minutes at $36^{\circ} \mathrm{C}$ as described. After the first heatshock, embryos were transferred to apple-juice plates and maintained at room temperature. Second and third heatshocks were carried out 2 and 4 hours after the start of the first heatshock. The embryos were transferred to apple-juice plates and maintained for different time periods until they were dechorionated and fixed in 4\% formaldehyde. Heatshocked Can tonS and non-heatshocked CantonS and HS-wg embryos were used as a control. A slight increase in background was observed as a general effect of heatshock.

\section{Whole-mount antibody staining}

Embryos were fixed in $4 \%$ formaldehyde and prepared for single or double antibody staining (van den Heuvel et al., 1989).

Antibodies were kindly provided by E. Wieschaus (antiarmadillo), T. Kornberg ( anti-engrailed), M. Wilcox (anti-Ubx), M. van den Heuvel (anti-wingless) and C. Goodman (anti- $\beta$-galac tosidase).

\section{Whole-mount RNA in situ}

RNA in situ hybridization on whole-mount embryos using digoxigenin-labeled DNA probes was performed according to a modification of the protocols of Tautz and Pfeiffle (1989) and D. Andrew (personal communication). Embryos were collected, heatshocked, fixed in formaldehyde and prepared for hybridization.

Probes were made of the following purified inserts:

$2.9 \mathrm{~kb}$ FnuDII - PvuII wingless sequences used to make the HS$w g$ construct (Rijsewijk et al., 1987);

240 bp EcoRI-SphI most 5' fragment of wingless cDNA, specific for the endogenous transcript (Rijsewijk et al., 1987);

$3.5 \mathrm{~kb}$ EcoRI fragment of patched DNA (Hooper and Scott, 1989); $2.4 \mathrm{~kb}$ EcoRI fragment of armadillo DNA (Riggleman et al., 1989);

$1.0 \mathrm{~kb}$ EcoRI fragment of cubitus interruptus Dominant DNA (Orenic et al., 1990);

1-3 $\mu \mathrm{g}$ of purified insert and $2 \mathrm{mg} / \mathrm{ml}$ hexanucleotide primers (Pharmacia) were boiled, chilled on ice and added to a mixture of hexanucleotide mix, dNTP labeling mix and Klenow fragment (as described in Genius protocol, Boehringer Mannheim). After 
overnight incubation at $14^{\circ} \mathrm{C}, 250 \mathrm{U} / \mathrm{ml}$ Klenow was added and the mixture was incubated for another 4 hours at room temperature. The probe was precipitated, washed, dissolved in TE containing $0.2 \%$ SDS and incubated for 2 hours prior to use at $37^{\circ} \mathrm{C}$ to prevent the probe from sticking to the plastic tube. Hybridization was done in a final volume of $200 \mu \mathrm{l}$ using $100 \mu \mathrm{l}$ of pretreated embryos with a probe concentration of approx. $2 \mathrm{ng} / \mu \mathrm{l}$. After hybridization, the washed embryos were incubated for 1 hour with anti-digoxigenin-alkaline phosphatase antibody $(1: 1000)$ that was preabsorbed against embryos for 2 hours at room temperature. Staining was performed using NBT and X-phosphate as substrates. After dehydration, embryos were transferred to methylsalicylate and mounted in Araldite.

\section{Results}

\section{Ubiquitous wingless expression results in naked ventral cuticle pattern}

To study the effect of ectopic wingless expression on the cuticle pattern and on the expression of segmentation genes, we made a line of transgenic flies (HS- $w g$ ) in which the wingless gene is controlled by the $h s p 70$ promoter. These flies were homozygous viable but weak; the insert maps to cytological location 66A/B. Individually staged embryos were shocked for 20 minutes at $36^{\circ} \mathrm{C}$, kept for 2 days and the cuticle prepared. rosy $y^{506}$ embryos were used as a control (Materials and methods).

In HS-wg two heatshock-sensitive periods during embryogenesis could be distinguished (Fig. 1). The first period is during late blastoderm (stage 5 [3], Lawrence and Johnston, 1989; Wieschaus and Nüsslein-Volhard, 1986) when heatshock results in a dramatic but incomplete loss of ventral denticle structures. This is the stage during which, in wild-type embryos, the wingless protein is first detected. The second period is later and longer, spanning from when the germ band is fully extended (stage 8 [3]) until germ band shortening (stage 12). The most extreme phenotype found after heatshock in this period was a lack of all abdominal denticle bands (Fig. 2B); we call this the HS- $w g$ phenotype. Some denticles (such as the T1 beard) are unaffected, showing that ectopic wingless changes the pattern of the cuticle without interfering with the ability to make denticles as such (Fig. 2C).

In wild-type embryos, many interactions between segment polarity genes are believed to take place during this second sensitive period. An indication for this is that expression of wingless and engrailed is altered at stage 9 to 11 in most segment polarity mutants (van den Heuvel et al., unpublished data).

HS-wg embryos heatshocked before stage 5 [3] do not survive to make cuticle, but were not studied in detail, while those shocked during stages 12 to 15 make a cuticle with a normal pattern.

We compared the complete HS-wg pattern to wild type. In the wild-type ventral abdomen, naked cuticle is characteristic of the posterior region of the segment, including parts both anterior and posterior to the parasegment border (Lohs-Schardin et al., 1979; Figs 2A and 7B). Each wildtype segment consists of a larger anterior and a smaller posterior compartment and these alternate throughout the 14

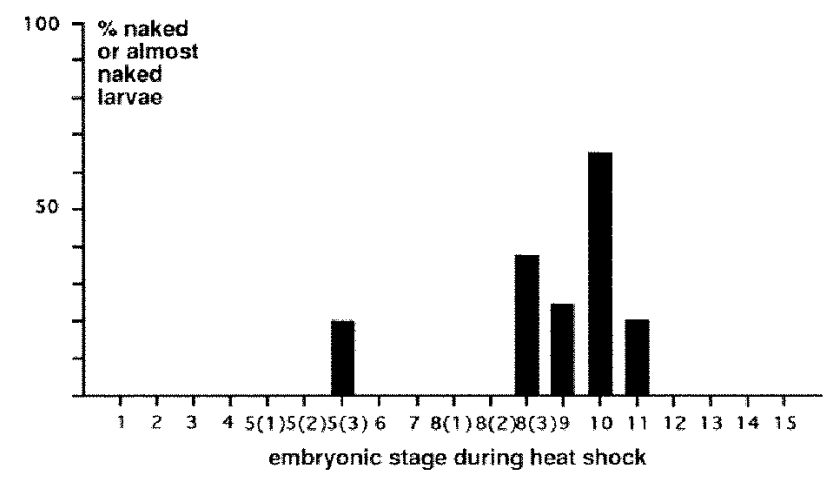

Fig. 1. Percentage of HS-wg embryos that show naked or almost naked larval ventral cuticle as a result of uniform wingless expression at different developmental stages.

Notes

(1) HS-wg embryos of developmental stages 0 to 15 (Wieschaus and Nüsslein-Volhard, 1986) were heatshocked for 20 minutes at $36^{\circ} \mathrm{C}$ (Materials and methods).

(2) HS-wg embryos heatshocked during stages 1 to 5 [2] of development did not survive to generate cuticle. The differences in cuticle phenotype of HS-wg embryos heatshocked during stages 5[3] to stage 11 are described in the Results section. Embryos heatshocked during stages 12 to 15 showed a normal cuticle phenotype. HS-wg embryos with abnormal cuticle phenotype did not hatch.

(3) We heatshocked different numbers of embryos of each developmental stage: 46 at stage 5[3]; 25 at stage $6 ; 14$ at stage 7 ; 21 at stage $8[1] ; 17$ at stage 8[2]; 29 at stage 8[3]; 24 at stage 9; 35 at stage $10 ; 10$ at stage $11 ; 8$ at stage $12 ; 11$ at stage $13 ; 41$ at stage $14 / 15$.

(4) Heatshocked rosy ${ }^{506}$ embryos of all described developmental stages were used as a control. In most cases rosy $y^{506}$ larvae hatched after two days with wild-type cuticle pattern; in some cases larvae were found with fused denticle belts.

parasegmental compartments in the main part of the body (Martinez-Arias and Lawrence, 1985). The compartments have been precisely mapped in the larva using an engrailedlac Z construct (Hama et al., 1990) so that we know which structural elements are anterior and which posterior and where they are located within the compartments. In the HS$w g$ phenotype, parts of the wild-type pattern appear unchanged while other parts are not present; probably the response of any particular element in the pattern is characteristic of the level in the segment from which it derives. For example, the beard, which is formed by the posterior region of the anterior segmental compartment of T1 (called T1a) is intact in the HS-wg phenotype (Fig. 2C). Dorsally, the sharply defined hairs characteristic of the most anterior region of the T2a compartment are absent but the similar hairs of the T3a compartment are not (Fig. 2D). In wildtype larvae, these latter hairs are formed further back in T3 than in T2 (Hama et al., 1990) suggesting that the part of the pattern eliminated includes only the anterior half of the anterior compartments - just sufficient to remove the denticle bands ventrally, the $\mathrm{T} 2$ anterior dorsal denticles, but not to affect the beard or the T3 anterior dorsal denticles. Ventrally, the first row of abdominal denticles actually belongs to the posterior compartment (Lohs-Schardin et al., 1979; Hama et al., 1990) and these are also eliminated; it 

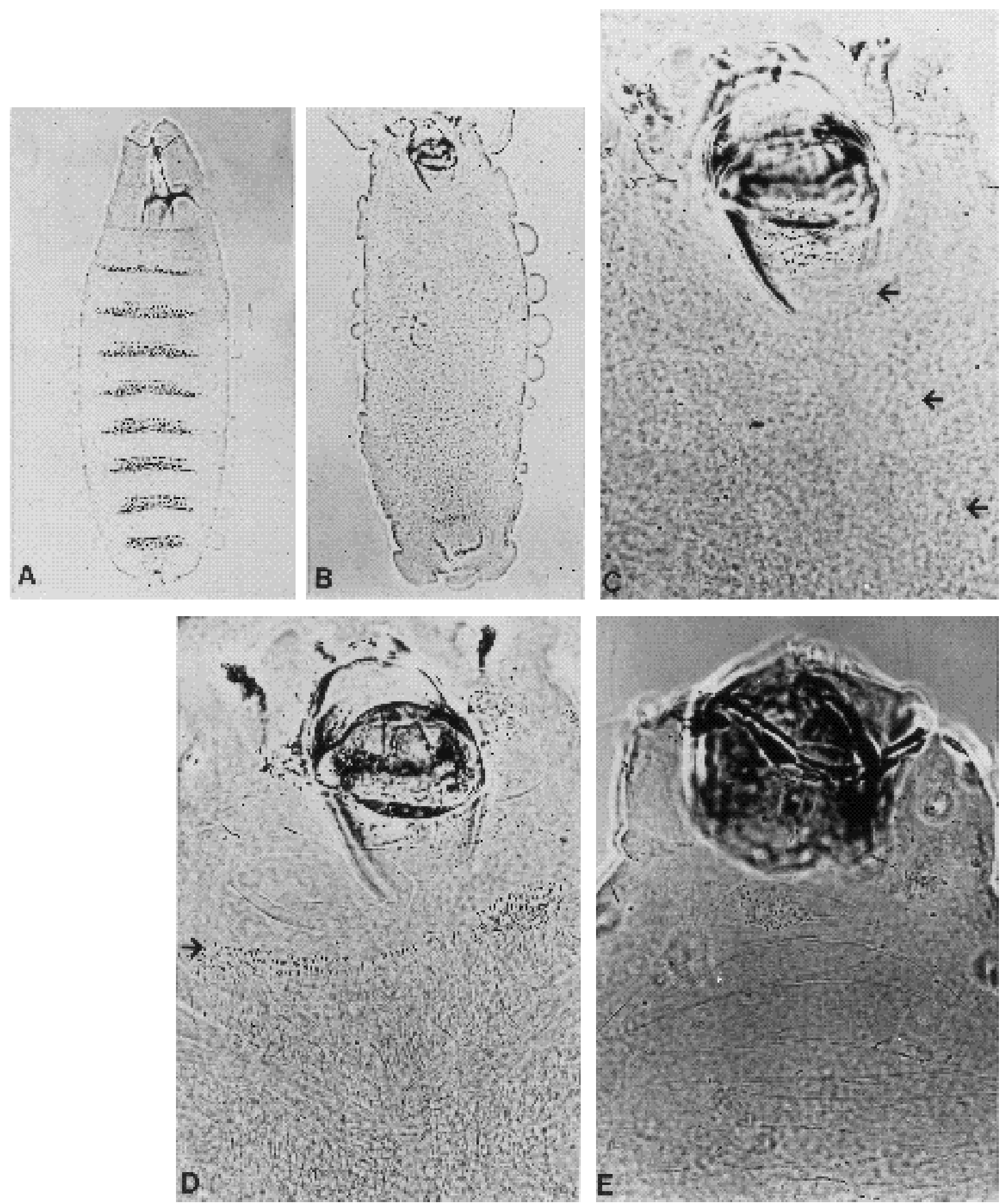

Fig. 2. Comparison of cuticle phenotype of heatshocked rosy ${ }^{506}$ (A), heatshocked HS-wg (B, C and D) and naked7E89 (E) larvae.

Anterior is up. (A) Ventral view of heatshocked rosy ${ }^{506}$ larval cuticle. Note the presence of denticle belts in the anterior portion of each segment. (B) Ventral view of heatshocked HS-wg larval cuticle. Uniform wingless expression results in a complete naked cuticle, except for the beard (shown in C), the tuft and the Fell. (C) Detail of HS-wg larva in B, showing the ventral cuticle with misformed head, the T1 beard and the Keilin's organs indicated by the arrows. (D) Detail of HS-wg larva in B, showing the dorsal cuticle in the head region. The most anterior row of hairs is located in compartment T3a, indicated by the arrow. (E) Detail of naked ${ }^{7 E 89}$ larvae with misformed head, naked ventral cuticle and beard. 
follows that at least part of the posterior compartment is not present in the HS-wg phenotype.

Structures near the parasegment border, such as the Keilin's organs (Fig. 2C) and some other sensory structures are not eliminated and this, as well as the normal size of the beard, suggests that those parts of the pattern that remain are normal or nearly so. Outside the parasegmental trunk there are also effects - the head is misformed (Fig. 2B) and so are parts of the tail. The A9 tuft develops as in wild type.

Partial phenotypes, observed after heatshocking during all stages between 5 [3] and 11, suggest a hierarchy - the regions of denticles are removed in a specific order. When the phenotype is weak, only the two most anterior rows of denticles are removed, resulting in a narrower denticle band. As the phenotype becomes more severe, the next most anterior row is removed and those elements characteristic of the posteriormost part of the denticle belt - the last row is finer and smaller and trails out further dorsally - are unaffected. A still further increase in the phenotype removes more of the denticle bands, particularly near the ventral midline, so that the bands become divided into two lateral patches.

\section{Ectopic wingless protein induces endogenous wingless} expression in a specific pattern

A 20 minute heatshock at $36^{\circ} \mathrm{C}$ produces a strong response in HS- $w g$ embryos, resulting in a high uniform level of wingless protein (Fig. 3A, B). Until 45 minutes after heatshock there is universally high levels of wingless protein but by 1.5 hours most ectopic wingless protein has disappeared, leaving a normal pattern of wingless expression. However, by 3 hours after heatshock, two new wingless domains appear, which are not present in wild-type embryos at this stage. In wild-type stage- 10 embryos, wingless is expressed in 14 stripes; the thoracic and abdominal stripes being split into ventral stripes and dorsolateral patches (van den Heuvel et al., 1989; Fig. 4A, G). In HS-wg embryos, high levels of ectopic wingless antigen can be detected in a large dorsal patch and lower levels in a stripe in the ventral region (Figs 4B, H, and 7A). Ventrally, protein can be detected between the ectopic and the normal stripes, but this is probably due to spreading of the secreted protein the RNA is localized strictly to cells in the two stripes. Using a probe specific for endogenous wingless RNA that distinguished it from the product of the HS-wg construct, we determined that the newly formed wingless comes from the endogenous gene (data not shown).

When embryos are heatshocked for 20 minutes, only a few percent of the embryos show the induction of endogenous wingless in the ectopic domain after 3 hours. Since the effect of heatshock on cuticle phenotype is restricted to a certain rather limited period in development, we heatshocked three times for 20 minutes with intervals of 2 hours between the start of each heatshock to increase the chance of hitting the sensitive period (Materials and methods). In this way, we are able to obtain a higher percentage of the embryos showing the described phenotype. The same temporal pattern of wingless expression is observed (disappearance of HS- $w g$ protein after 1.5 hours and induction of endogenous wingless after 3 hours), but now almost all of stage 10 HS- $w g$ embryos have the ectopic wingless domain 3 hours after the last heatshock. Canton $S$ control embryos do not exhibit the change in wingless expression after three heatshocks. HS-wg embryos treated in this way show a developmental delay; many embryos of a 1-6 hour egg collection, heatshocked three times with 2 hour intervals between the heatshocks and then aged for 3 hours, are still in stages 10 to 11 .

\section{Ectopic wingless expression results in expansion of the engrailed expression domain in a posterior direction}

In every parasegment in the embryo, an anterior stripe of cells expresses engrailed (Fig. 4D, G). In HS-wg embryos, collected for 1 to 6 hours and heatshocked once for $20 \mathrm{~min}$ utes at $36^{\circ} \mathrm{C}$, a change in engrailed expression is observed 1 to 1.5 hours after heatshock, resulting in a broader engrailed stripe. 3 hours after heatshock, the engrailed stripe has broadened further, spanning maximally about one-third of the segment. This effect is seen in only a few percent of the embryos. When we used the multiple heatshock regime (Materials and methods), virtually all of the HS- $w g$ embryos showed a broader engrailed domain. In the HS-wg embryos, treated in this way, no change in the engrailed pattern is detected 30 minutes after the last heatshock (when the level of wingless protein is universally high). However, by 1.5 hours after the last shock, the engrailed stripe has begun to broaden and this continues progressively. By 3 hours, the engrailed domain has broadened further, apparently to a maximum of half the width of the parasegment. Just posterior to the broadened engrailed stripe, grooves form and these are much deeper than the normal parasegment grooves - which can still be seen at the anterior limits of the engrailed bands (Figs 4E, 7A). Heatshocked Canton $S$ control embryos do not show this change in engrailed expression or formation of the new deep grooves.

We determined the direction of broadening of the engrailed stripe with reference to fixed landmarks. The anterior limits of the even-skipped stripes mark the oddnumbered parasegment borders; we therefore used an evelac $Z$ construct to label them (Lawrence et al., 1987). The results revealed that the original parasegment borders remain unchanged while the engrailed stripes broaden posteriorly (Fig. 5).

Double labelling for both wingless and engrailed showed that the most prominent wingless stripe is the normal one found just anterior to the parasegment boundary; the ectopic wingless dorsal patch is located just posterior to the engrailed domain and the deep groove (Fig. 4E,H).

\section{Expression of several segmentation and homeotic genes changes as a consequence of ectopic wingless expression}

To understand more about how the HS-wg phenotype is established, we studied the changes in expression of several segmentation and selector genes caused by ubiquitous wingless protein. We concentrated on a gene thought to function in the wingless-signalling pathway (armadillo) and three genes (patched, cubitus interruptus Dominant and $U b x$ ) that are regulated by engrailed and essential for correct formation of the anterior compartment. 
armadillo RNA is normally expressed uniformly but the protein concentration is uneven; it is found at high levels in those cells where wingless is expressed (Riggleman et

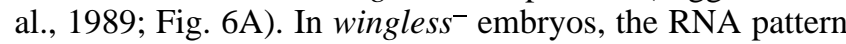
is unchanged, while armadillo protein is distributed at uniform low levels (Riggleman et al., 1990). When HS-wg embryos are shocked three times and kept for 3 hours (Materials and methods), the armadillo RNA shows the normal pattern of uniform distribution. The protein distribution is quite different from that in wild-type embryos, being evenly distributed and showing intense staining throughout the embryo (Fig. 6B).

The patched gene encodes a transmembrane protein which, by the end of germ band extension, is expressed in stripes that correspond to the anterior compartment (Hooper and Scott, 1989; Nakano et al., 1989; Fig. 6E). By stage 12 , patched transcripts disappear from the middle of each stripe so that each original stripe becomes two narrow ones. In HS-wg embryos, 3 hours after the last shock, the patched domain becomes confined to those cells that do not express engrailed. The anterior border of the patched stripe coincides with the deep groove that marks the posterior limit of the broadened engrailed stripe (Fig. 6F).

The cubitus interruptus Dominant gene encodes a protein with a zinc-finger motif and is expressed in the anterior compartments (Orenic et al., 1990; Fig. 6H). In HS-wg embryos, after heatshock treatment, cubitus interruptus Dominant RNA expression becomes restricted to those cells that are outside the expanded engrailed domain and therefore coincides with the patched stripe (Fig. 6I).

The $U b x$ gene is a member of the bithorax complex and is expressed in a parasegmental register; the anterior limit of $U b x$ is at the anterior boundary of parasegment 5 (White and Wilcox, 1985; Fig. 6K). In the wild type, expression of Ubx is high in the anterior compartments of parasegments 7-12 and low in the posterior compartment where engrailed protein is present and suppresses transcription of Ubx. In HS-wg embryos, after shock, we observe that the outcome expected in parasegments 7-12 $U b x$ protein is only seen in those cells that do not express engrailed (Fig. 6L).

\section{The phenotype of HS-wg embryos and the segment polarity} mutant naked are similar

The cuticle phenotype and pattern of gene expression in HS-wg embryos strongly resembles the naked phenotype (Jürgens et al., 1984; Martinez-Arias et al., 1988). naked is a segment polarity gene, whose molecular nature is unknown. naked ${ }^{-}$embryos are shorter than HS-wg, but are otherwise similar. As in the HS-wg phenotype after heat shock, the naked $^{-}$embryos have no denticle bands in the ventral cuticle (apart from the beard in T1; Fig. 2E) but do have the Fell and the A9 tuft. The Keilin's organs are present but, unlike those in HS-wg embryos, are abnormal. Often they consist of four or more hairs, rather than three, and occasionally there are three rather than two organs per segment (Simcox et al., 1989).

The expression patterns of wingless and engrailed in HS$w g$ embryos, 3 hours after heat shock, are similar to those in naked $^{-}$embryos (Figs $4 \mathrm{C}, \mathrm{F}, \mathrm{I}$ ). As with HS-wg, we used embryos carrying an eve-lac $Z$ construct to determine that the engrailed stripe broadens in the posterior direction.
There is a similar deep groove formed at the posterior limit of the engrailed domain, and anterior to the ectopic wing less stripe (Fig. 4F). Moreover, the distributions of patched and cubitus interruptus Dominant RNA as well as Ubx protein were the same in the two kinds of embryos (Figs 6G, $\mathrm{J}, \mathrm{M})$. For armadillo, the RNA pattern is identical but the protein pattern differs. In naked-embryos, there is an equal distribution of protein (as in HS-wg) but, in addition, there are two rows of cells that stain more intensely with the armadillo antibody (Fig. 6C, D). These cells are located in the wingless-expressing half of the parasegment.

\section{Discussion}

The striking and defined new phenotype formed when wing less protein is made ubiquitously favors the hypothesis that, in wild-type embryos, local accumulation of wingless in the segment is essential for correct pattern formation. When wingless is expressed throughout the embryo, larvae lose specific pattern elements, resulting in a complete naked ventral cuticle. We have described some of the many correlated changes in HS-wg embryos in expression of segment polarity and selector genes.

One simple model for wingless function can be considered: the amount of wingless present in a cell in the segment could be instructive for its fate. Within the anterior compartment of the wild-type segment, the local concentration of wingless protein might determine the local pattern - this active wingless protein forming a concentration gradient in the anterior compartment from a high level near the posterior border (where the cuticle is naked) to a low level at the anterior border (where the cuticle forms denticles). Lack of wingless might then produce a continuous mass of denticles, as observed. A uniformly high concentration of wingless protein would be predicted to produce an even field of naked cuticle, as seen in the HS-wg phenotype.

However, the proposed model leaves much unexplained: in the HS-wg phenotype, the naked cuticle is not homogeneous, in each metamer there is a posterior domain where there is engrailed expression and an anterior region where wingless protein is present. In patched, naked ${ }^{-}$and shaggy/zeste-white $3^{-}$, ectopic expression of engrailed and wingless is restricted to the same two domains, suggesting that only cells in these domains are capable of expressing either engrailed or wingless but not both (Martinez-Arias et al., 1988; Perrimon and Smouse, 1989). This predisposition of cell fate could be determined by expression of earlier acting pair-rule genes (Ingham et al., 1991). In the extended germ band HS-wg embryo, where the two cell types meet, a new deep groove forms (Fig. 7). The loss of pattern elements that form near the segment border, specifically the denticle bands on both sides of it, could be due to either respecification or to cell death - there probably is cell death in HS-wg embryos as they are somewhat smaller than wild type.

The maintenance of the parasegment borders is dependent on wingless and engrailed and, as we show here, they survive transient ubiquitous expression of wingless. The pattern near the parasegment border seems to be unaffected 
A

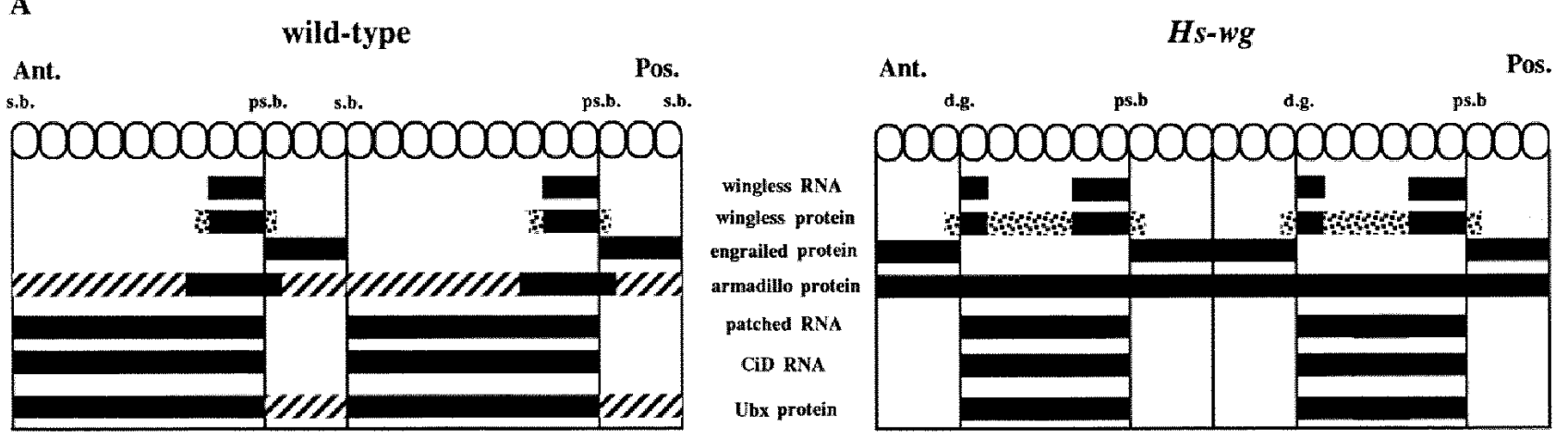

$\mathbf{B}$

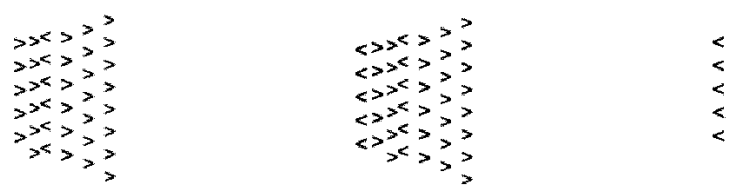

Fig. 7. Schematic representation of the expression pattern of several segmentation genes and cuticle phenotype in wild type and HS- $w g$. (A) Expression of segmentation and selector genes in a stage 10/11 wild-type and HS-wg embryo, 3 hours after heatshock (Materials and methods). A schematic drawing of two adjacent segments is shown. At this stage of embryogenesis, each segment is about 12 cells in width. The domain of expression of each gene is depicted by the black boxes. Directly after heatshock in HS-wg embryos wingless is expressed uniformly throughout the segment. Here, wingless expression is shown 3 hours after heatshock; the HS-wg RNA has disappeared and an ectopic domain of endogenous wingless RNA is observed just posterior to a deep groove. This deep groove is formed in HS-wg embryos posterior to the new engrailed domain (Fig. 4E). The wingless protein is detected at a low level between the ectopic wingless domain and the normal wingless stripe (Fig. 4B), most likely due to spreading of the protein (spread protein is indicated as dots). In wild-type embryos, the protein can also be detected outside the cells where it is made (shown by the dots; Van den Heuvel et al., 1989). engrailed in HS-wg embryos has broadened in the posterior direction, spanning half a segmental unit (Fig. 4E), while the high level of armadillo protein, normally only found in the wingless domain (Fig. 6A), has extended to the whole segment (Fig. 6B). The low basal level of armadillo protein in wild-type embryos is shown by stripes. In HS-wg embryos patched RNA, cubitus interruptus Dominant RNA and $U b x$ protein expression seem to correlate with and perhaps follow the altered distribution of engrailed. In the wild type, engrailed represses patched (Hildalgo and Ingham, 1990), cubitus interruptus Dominant (Eaton and Kornberg, 1990) and Ubx (MartinezArias and White, 1988) in a temporally and spatially distinct pattern. In HS-wg, where we observe an expansion of engrailed, we see a retraction of patched (Fig. 6F) and cubitus interruptus Dominant (Fig. 6I). Ubx is down-regulated in the anterior half of parasegments 712, where engrailed is expressed at a high level (Fig. 6L). The lower level of $U b x$ in the posterior compartment of the wild-type segment is indicated by the stripes. (Abbreviations: Ant., anterior; Pos., posterior; s.b., segment border; ps.b., parasegment border; d.g., deep groove.) (B) Location of denticle belts and naked cuticle in wild-type and HS-wg larvae. In wild-type embryos, abdominal segments are characterized by a belt of denticles in the ventral cuticle of which the first row is in the posterior segmental compartment of the preceding segment, while the other approx. six rows are present in the anterior part of the anterior segmental compartment. The position of the larval belts is shown relative to the embryonic gene expression patterns in A. The more posterior part of the anterior segmental compartment of the larval segment is naked, corresponding to the region where wingless is expressed in the embryonic segment. In HS-wg embryos the denticle belts are lost, resulting in a complete naked segment.

with normally orientated Keilin's organs and other sensilla formed in their usual positions. Intermediate cuticle phenotypes suggest the pattern is altered progressively out from the segment border since denticle rows are lost, proceeding from the most anterior row in a posterior direction. Changes in gene expression also appear to spread out from the borders - the engrailed stripe broadens progressively; 1.5 hours after heatshock when most of the ectopic wing less product has decayed, the engrailed stripe begins to broaden from its posterior margin to a maximum of about half the segment width (Fig. 7).

One general explanation for these progressive changes is that the requirements for (or the effects of) wingless protein could vary quantitatively across the segment. There is other evidence for this: if the wingless gene is inactivated (by temperature shifts using a wingless ${ }^{\text {ts }}$ mutant) at 5-6 hours of development, the ventral cuticle is almost entirely covered with denticles. After temperature shifts at later and later times during the extended germband stages in the embryo, the cuticle pattern progressively approaches wild type as a naked area first appears near the segment border and then extends towards the anterior (Bejsovec and Martinez-Arias 1991).

The effects of uniform wingless expression on the cuticle phenotype seem to be restricted to two periods in development: stage 5(3) and stages 8(3) to 11. During the later period, in particular around stage 9-10, a dramatic change in engrailed expression is observed in HS-wg embryos. Interestingly, this sensitive period in HS-wg embryos coincides with the developmental stage during which engrailed expression is dependent on the presence of wingless protein (Heemskerk et al., 1991). 
Possibly, the action of wingless is mediated in part by the armadillo protein. It has been shown that the gradient distribution of the armadillo protein depends on wingless (Riggleman et al., 1990) and, in HS-wg embryos intense armadillo staining is seen in virtually all the cells of the segment. This ubiquitous response to the wingless signal indicates that most cells in the segment can respond by changing the distribution of armadillo and generating naked cuticle. This might mean that the receptors for the wingless signal are present in many more cells than where wingless is expressed in the wild-type segment. Normally, wingless could act as a local ligand, triggering a response only in cells where it is expressed or cells to which the protein can spread. The amount of wingless and consequently of armadillo, could determine what type of cuticle is generated. During various other patterning events in Drosophila, regional specification is similarly regulated by locally acting ligands and more widespread receptors (Stevens et al., 1990; Stein et al., 1991; Krämer et al., 1991).

The HS-wg phenotype shows a striking similarity with the naked ${ }^{-}$phenotype. The expansion of the engrailed domain in a naked ${ }^{-}$background led to the suggestion that naked might act as a repressor of engrailed in the anterior compartment (Martinez-Arias et al., 1988). Our results suggest that any repression of engrailed by naked could be overruled by induction of engrailed by wingless. The mechanism of the interactions between naked and engrailed is not known, since the molecular structure of the naked product has not been established. The segment polarity mutant shaggy/zeste-white 3 has an almost identical phenotype to naked (Perrimon and Smouse, 1989). shaggy/zeste-white3 encodes a serine-threonine protein kinase, highly homologous to the mammalian protein glycogen-synthase-kinase 3 (Siegfried et al., 1990; Bourouis et al., 1990). The repressive effect of shaggy/zeste-white 3 on engrailed expression could be brought about by phosphorylation and be competed by the activating action of wingless. The relative amount of wingless present could determine the outcome of this competition.

We would like to thank Lee Fradkin, Greg Gibson, John Klingensmith, Calvin Kuo, Javier Sampedro and Marcel van den Heuvel for useful comments on the manuscript. R.N. is an investigator of the Howard Hughes Medical Institute. These studies were supported by the Howard Hughes Medical Institute, the Netherlands Cancer Institute, the Netherlands Foundation for Fundamental Research (ZWO) and the Medical Research Council.

\section{References}

Babu, P. (1977). Early developmental subdivisions of the wing disk in Drosophila. Mol. Gen. Genet. 151, 289-294.

Baker, N. E. (1987). Molecular cloning of sequences from wingless, a segment polarity gene in Drosophila: The spatial distribution of a transcript in embryos. EMBO J. 6, 1765-1773.

Baumgartner, S., Bopp, D., Burri, M. and Noll, M. (1987). Structure of two genes at the gooseberry locus related to the paired gene and their spatial expression during Drosophila embryogenesis. Genes Dev. 1, 1247-1267.

Bejsovec, A. and Martinez Arias, A. (1991). Roles of wingless in patterning the larval epidermis of Drosophila. Development 113, 471485

Bourouis, M., Moore, P., Puel, L., Grau, Y., Heitzler, P. and Simpson, P. (1990). An early embryonic product of the gene shaggy encodes a serine/threonine protein kinase related to $C D C 28 / c d c 2+$ subfamily. EMBO J. 9, 2877-2884.

Bradley, R. S. and Brown, A. M. (1990). The proto-oncogene int-1 encodes a secreted protein associated with the extracellular matrix. EMBO J. 9, 1569-1575.

DiNardo, S., Sher, E., Heemskerk-Jorgens, J., Kassis, J. and O'Farrell, P. (1988). Two-tiered regulation of spatially patterned engrailed gene expression during Drosophila embryogenesis. Nature 332, 604609.

Eaton, S. and Kornberg, T. B. (1990). Repression of $c i-D$ in posterior compartments of Drosophila by engrailed. Genes Dev. 4, 1068-1077.

Fjose, A., McGinnis, W. J. and Gehring, W. J. (1985). Isolation of a homeobox-containing gene from the engrailed region of Drosophila and the spatial distribution of its transcript. Nature 313, 284-289.

González, F., Swales, L., Bejsovec, A., Skaer, H. and Arias, A. M. (1991). Secretion and movement of wingless protein in the epidermis of the Drosophila embryo. Mech. Dev. 35, 43-54.

Hama, C., Ali, Z. and Kornberg, T. B. (1990). Region-specific recombination and expression are directed by portions of the Drosophila engrailed promoter. Genes Dev. 4, 1079-1093.

Heemskerk, J., DiNardo, S., Kostriken, R. and O'Farrell, P. H. (1991). Multiple modes of engrailed regulation in the progression towards cell fate determination. Nature 352, 404-410.

Hidalgo, A. and Ingham, P. (1990). Cell patterning in the Drosophila segment: spatial regulation of the segment polarity gene patched. Development 110, 291-301.

Hooper, J. E. and Scott, M. P. (1989). The Drosophila patched gene encodes a putative membrane protein required for segmental patterning. Cell 59, 751-765.

Ingham, P. W., Taylor, A. M. and Nakano, Y. (1991). Role of the Drosophila patched gene in positional signalling. Nature 353, 184187.

Jue, S., Bradley, R., Rudnicki, J., Varmus, H. and Brown, A. (1992). The mouse Wnt-1 gene can act as a paracrine mechanism in transformation of mammary epithelial cells. Mol. Cell. Biol. 12, 321-328.

Jürgens, G., Wieschaus, E., Nüsslein-Volhard, C. and Kluding, $\mathbf{H}$. (1984). Mutations affecting the pattern of the larval cuticle in Drosophila melanogaster. II. Zygotic loci on the third chromosome. Roux's Arch. Dev. Biol. 193, 283-295.

Karess, R. E. and Rubin, G. M. (1984). Analysis of P transposable element functions in Drosophila.Cell 38, 135-146.

Kornberg, T., Siden, I., O'Farrell, P. and Simon, M. (1985). The engrailed locus of Drosophila: in situ localization of transcripts reveals compartment-specific expression. Cell 40, 45-56.

Krämer, H., Cagan, R. L. and Zipursky, S. L. (1991). Interaction of bride of sevenless membrane-bound ligand and the sevenless tyrosine-kinase receptor. Nature 352, 207-212.

Lawrence, P. A. and Johnston, P. (1989). Pattern formation in the Drosophila embryo: allocation of cells to parasegments by even-skipped and fushi tarazu.Development 105, 761-767.

Lawrence, P. A., Johnston, P., Macdonald, P. and Struhl, G. (1987). Borders of parasegments in Drosophila embryos are delimited by the fushi tarazu and even-skipped genes. Nature 328, 440-442.

Lawrence, P.A. (1992). The Making of A Fly. Oxford: Blackwell Scientific Publications.

Lohs-Schardin, M., Cremer, C. and Nusslein-Volhard, C. (1979). A fate map for the larval epidermis of Drosophila melanogaster: localized cuticle defects following irradiation of the blastoderm with an ultraviolet laser microbeam. Dev. Biol. 73, 239-255.

Martinez-Arias, A., Baker, N. and Ingham, P.W. (1988). Role of segment polarity genes in the definition and maintenance of cell states in the Drosophila embryo. Development 103, 157-170.

Martinez-Arias, A. and White, R. A. H. (1988). Ultrabithorax and engrailed expression in Drosophila embryos mutant for segmentation genes of the pair-rule class. Development 102, 325-338.

Martinez-Arias, A. and Lawrence, P. A. (1985). Parasegments and compartments in the Drosophila embryo. Nature 313, 639-642.

McCrea, P. D., Turck, C. W. and Gumbiner, B. (1991). A homolog of the armadillo protein in Drosophila (plakoglobin) associated with Ecadherin. Science 254, 1359-1361.

Moran, L., Mirault, M.-E., Tissières, A., Lis, J., Schedl, P., ArtavanisTsakonas, S. and Gehring, W. J. (1979). Physical map of two D. melanogaster DNA segments containing sequences coding for the 70,000 dalton heat shock protein. Cell 17, 1-8. 
Morata, G. and Lawrence, P. A. (1977). The development of wingless, a homeotic mutation of Drosophila. Dev. Biol. 56, 227-240.

Nakano, Y., Guerrero, I., Hidalgo, A., Taylor, A., Whittle, J. R. S. and Ingham, P. W. (1989). The Drosophila segment polarity gene patched encodes a protein with multiple potential membrane spanning domains. Nature 341, 508-513.

Nusse, R. and Varmus, H. E. (1992). Wnt genes. Cell 69, 1073-1087.

Nüsslein-Volhard, C. and Wieschaus, E. (1980). Mutations affecting segment number and polarity in Drosophila. Nature 287, 795-801.

Orenic, T. V., Slusarski, C., Kroll, K. L. and Holmgren, R. A. (1990). Cloning and characterization of the segment polarity gene cubitus interruptus Dominant of Drosophila. Genes Dev. 4, 1053-1067.

Papkoff, J. and Schryver, B. (1990). Secreted int-1 protein is associated with the cell surface. Mol. Cell Biol. 10, 2723-2730.

Peifer, M. and Wieschaus, E. (1990). The segment polarity gene armadillo encodes a functionally modular protein that is the Drosophila homolog of human plakoglobin. Cell 63, 1167-1178.

Perrimon, N. and Smouse, D. (1989). Multiple functions of a Drosophila homeotic gene, zeste-white 3, during segmentation and neurogenesis. Dev. Biol. 135, 287-305.

Préat, T., Thérond, P., Lamour-Isnard, C., Limbourg-Bouchon, B., Tricoire, H., Erk, I., Mariol, M.-C. and Busson, D. (1990). A putative serine/threonine protein kinase encoded by the segment-polarity fused gene of Drosophila. Nature 347, 87-89.

Riggleman, B., Schedl, P. and Wieschaus, E. (1990). Spatial expression of the Drosophila segment polarity gene armadillo is post-transcriptionally regulated by wingless. Cell 63, 549-560.

Riggleman, B., Wieschaus, E. and Schedl, P. (1989). Molecular analysis of the armadillo locus: uniformly distributed transcripts and a protein with novel internal repeats are associated with a Drosophila segment polarity gene. Genes Dev. 3, 96-113.

Rijsewijk, F., Schuermann, M., Wagenaar, E., Parren, P., Weigel, D. and Nusse, R. (1987). The Drosophila homolog of the mouse mammary oncogene int-1 is identical to the segment polarity gene wingless. Cell $\mathbf{5 0}$, $649-57$.
Sharma, R. P. and Chopra, V. L. (1976). Effect of the wingless ( $\mathrm{wg}^{\mathrm{l}}$ ) mutation on wing and haltere development in Drosophila melanogaster. Dev. Biol. 48, 461-465.

Siegfried, E., Perkins, L. A., Capaci, T. M. and Perrimon, N. (1990). Putative protein kinase product of the Drosophila segment-polarity gene zeste-white 3. Nature 345, 825-829.

Simcox, A., Roberts, I., Hersperger, E., Gribbin, C., Shearn, A. and Whittle, R. (1989). Imaginal discs can be removed from cultured embryos mutant for the segment polarity genes engrailed, naked and patched, but not from wingless. Development 107, 715-722.

Stein, D., Roth, S., Vogelsang, E. and Nüsslein-Volhard, C. (1991). The polarity of the dorsoventral axis in the Drosophila embryo is defined by an extracellular signal. Cell 65, 725-735.

Stevens, L. M., Frohnhöfer, H. G., Klingler, M. and Nüsslein-Volhard, C. (1990). Localized requirement for torso-like expression in follicle cells for development of terminal anlagen of the Drosophila embryo. Nature 346, 660-663.

Tautz, D. and Pfeiffle, C. (1989). A non-radioactive in situ hybridization method for the localization of specific RNAs in Drosophila embryos reveals translational control of the segmentation gene hunchback. Chromosoma 98, 81-85.

Török, I. and Karch, F. (1980). Nucleotide sequences of heat shock activated genes in Drosophila melanogaster. I. Sequences in regions of the $5^{\prime}$ and $3^{\prime}$ ends of the hsp 70 gene in the hybrid plasmid 56H8. Nucl. Acids Res. 8, 3105-3123.

van den Heuvel, M., Nusse, R., Johnston, P. and Lawrence, P. A. (1989). Distribution of the wingless gene product in Drosophila embryos: a protein involved in cell-cell communication. Cell 59, 739-749.

White, R. A. H. and Wilcox, M. (1985). Distribution of Ultra-bithorax proteins in Drosophila. EMBO J. 4, 2035-2043.

Wieschaus, E. and Nüsslein-Volhard, C. (1986). Looking at embryos. In Drosophila: A practical approach. (Edited by D. B. Roberts.) pp. 199227. Oxford: IRL Press. 
Fig. 3. A high uniform level of wingless protein is observed in HS-wg embryos after heatshock. HS-wg (A) and Canton $S$ (B) control embryos were heatshocked for 20 minutes at $36^{\circ} \mathrm{C}$ and incubated for 30 minutes before fixation and antibody staining (Materials and methods).

Fig. 4. wingless and engrailed protein expression pattern in whole-mount Canton S, heatshocked HS-wg and naked ${ }^{7 E 89}$ embryos at stage 10 of development (Wieschaus and Nüsslein-Volhard, 1986). Anterior is to the left, dorsal is up. A, B and C show a ventral surface view of the embryo; D, E and F give a sagittal section, while G, H and I are surface views. In the double-labeled embryo, wingless protein is black, engrailed is red. (A,D,G) Canton $S$ embryos stained for wingless (A), engrailed (D) or both proteins (G). (B,E,H) HS-wg embryos were heatshocked three times and maintained for 3 hours after the last heatshock before fixation (Materials and methods) and stained for wingless $(\mathrm{B})$, engrailed $(\mathrm{E})$ or both $(\mathrm{H})$. The deep groove posterior to the new engrailed domain is indicated by the arrow. (C,F,I) naked $^{7 \mathrm{E} 89}$ embryos stained for wingless $(\mathrm{C})$, engrailed $(\mathrm{F})$ or both (I). A similar deep groove as present in HS-wg embryos, can be seen in naked $^{7 E 89}$ (arrow).

Fig. 5. engrailed expression in HS-wg embryos broadens in the posterior direction. A double-labeled embryo, containing both the HS-wg gene and the even-skipped-lacZ gene (Lawrence et al., 1987) is shown, stained for engrailed protein (blue) and $\beta$ galactosidase protein (brown). The embryo was heatshocked three times and maintained for 3 hours before fixation (Materials and methods). Anterior is to the left and dorsal is up. The anterior edges of the odd-numbered parasegments are independently marked by the anterior sharp borders of the even-skipped-lacZ expression domains (e.g., arrowhead at parasegment 13). Here, as in wild type, this edge coincides with the anterior edge of the engrailed stripe. The engrailed stripes, which are abnormally broad in this heatshocked embryo, must therefore have broadened away from the parasegmental borders in the posterior direction.

Fig. 6. Comparison of expression patterns of several segmentation genes in whole-mount Canton S, heatshocked HS-wg and naked ${ }^{7 E 89}$ embryos at stage 10 of development. Anterior is to the left, dorsal is up. A-C and H-J show a surface view of the embryo, while E-G and $\mathrm{K}-\mathrm{M}$ are sagittal sections. HS-wg embryos were heatshocked three times and maintained for 3 hours after the last heatshock before fixation (Materials and methods). (A-C) Distribution of armadillo protein in Canton S (A), heatshocked HS-wg (B) and naked ${ }^{7 E 89}$ embryos (C). (D) Detail of Fig. 6C, showing two rows of cells in the naked ${ }^{7 E 89}$ embryo with higher intensity of armadillo staining in the wingless-expressing half of each segment. (E-G) patched RNA expression pattern in Canton $S$ (E), heatshocked HS-wg (F) and naked ${ }^{7 E 89}$ (G) embryos. (H-J) cubitus interruptus Dominant RNA expression pattern in Canton $S(\mathrm{H})$, heatshocked HS-wg (I) and naked ${ }^{7 E 89}(\mathrm{~J})$ embryos. (K-M) Ubx protein distribution in Canton $S(\mathrm{~K})$ heatshocked HS-wg (L) and naked ${ }^{7 E 89}(\mathrm{M})$ embryos. The newly formed deep groove in HS-wg and naked ${ }^{7 E 89}$ embryos is indicated by an arrow. Expression is detected in parasegments 5-13. 